\title{
Left atrial appendage closure devices for cardiovascular risk reduction in atrial fibrillation patients
}

This article was published in the following Dove Press journal:

Research Reports in Clinical Cardiology

13 May 2015

Number of times this article has been viewed

\author{
Ignacio Cruz-Gonzalez* \\ Juan Carlos Rama-Merchan* \\ Javier Rodriguez-Collado \\ Javier Martin-Moreiras \\ Alejandro Diego-Nieto \\ Antonio Arribas-Jimenez \\ Pedro Luís Sanchez
}

Department of Cardiology, University Hospital of Cardiology and IBSAL, Salamanca, Spain

*Ignacio Cruz-Gonzalez and Juan Carlos Rama-Merchan have contributed equally to this work and should be considered co-first authors

Correspondence: Ignacio Cruz-Gonzalez Department of Cardiology, University Hospital of Salamanca, Paseo de San Vicente 58-187, 37007 Salamanca, Spain Tel +3492329I 100 (ext 55356) Fax +34923270008

Email cruzgonzalez.ignacio@gmail.com
Abstract: Atrial fibrillation $(\mathrm{AF})$ is the most common sustained arrhythmia in clinical practice. $\mathrm{AF}$ is associated with a 4-5-fold increased risk of stroke and systemic embolism. Oral anticoagulant is the first-line therapy for this purpose, but it has various limitations and is often contraindicated or underutilized. Autopsy and surgical data have suggested that $90 \%$ of atrial thrombi in nonvalvular AF patients originate from the left atrial appendage, leading to the development of percutaneous closure for thromboembolic prevention. This paper examines the current evidence on left atrial appendage closure devices for cardiovascular risk reduction in AF patients.

Keywords: atrial fibrillation, left atrial appendage, stroke, oral anticoagulant, percutaneous closure, thromboembolic prevention

\section{Introduction}

Atrial fibrillation (AF) is the most common sustained arrhythmia, and it is associated with substantial morbidity and mortality. ${ }^{1,2}$ The prevalence of AF in the United States is expected to rise up to 5.6-12 million in $2050 .{ }^{3}$ Patients with AF have a 5-fold increased risk of stroke, and it is estimated that $15 \%-20 \%$ of all strokes are attributable to $\mathrm{AF}^{4}$ Moreover, strokes related to $\mathrm{AF}$ have been observed to be associated with a higher mortality and morbidity when compared with non-AF strokes, emphasizing the need for more effective stroke prevention in these patients. ${ }^{5}$ The risks of thromboembolic complications and stroke remain the same regardless of whether a person has paroxysmal, persistent, or long-standing persistent $\mathrm{AF}^{6-8}$ In clinical practice, the $\mathrm{CHADS}_{2}$ and $\mathrm{CHA}_{2} \mathrm{DS}_{2}-\mathrm{VASc}$ scoring systems provide risk stratification data on the likelihood of stroke or systemic embolism and are used to guide therapy (anticoagulation or aspirin). ${ }^{9}$

Oral anticoagulants (OACs) reduce the risk of thromboembolism, yet they are underused. ${ }^{10-12}$ The warfarin efficacy to prevent thromboembolism in patients with AF and risk factors for stroke has been well established. ${ }^{13,14}$ However, the biggest risk of long-term warfarin therapy is major bleeding, which has an incidence of $2 \%-4 \%$ per year, and it can be even higher if predisposing factors are present. ${ }^{15-17}$ Also, warfarin is limited by a narrow therapeutic window, inconvenience of frequent monitoring, and multiple medication and food interactions. ${ }^{18}$ Previous studies have suggested that warfarin discontinuation rates are estimated to be as high as $38 \%$ per year. ${ }^{14}$

Novel OACs are noninferior or superior to warfarin for the prevention of stroke and systemic embolism and they do not require ongoing monitoring. ${ }^{15-17,19}$ However, the risk of bleeding, long-term compliance, cost, and the lack of an available antidote 
represent substantial challenges for the management of stroke prevention in patients with $\mathrm{AF}^{20}$

In patients with AF, blood flow velocity in the left atrial appendage (LAA) frequently decreases, resulting in stasis and increasing the probability of thrombus formation..$^{21,22}$ Autopsy and surgical data have suggested that $90 \%$ of atrial thrombi in nonvalvular AF (NVAF) patients originate from the LAA. ${ }^{23}$ Also, thrombi have been detected by transesophageal echocardiography (TEE) in approximately $15 \%$ of patients with AF. ${ }^{24,25}$ Accordingly, several transcatheter LAA closure devices to reduce the risk of stroke and to obviate the need for long-term systemic anticoagulation therapy in patients with $\mathrm{AF}$ have been developed.

In this review, we summarize the current status of LAA closure devices for cardiovascular risk reduction in $\mathrm{AF}$ patients.

\section{Transcatheter devices for left atrial appendage closure}

Percutaneous LAA closure has been shown as an alternative strategy to chronic warfarin therapy for stroke prophylaxis in patients with NVAF. ${ }^{26}$ Consequently, several transcatheter devices for LAA closure has been developed and tested. The most studied include the PLAATO system (ev3 Endovascular, Plymouth, MN, USA), the WATCHMAN device (Boston Scientific, Plymouth, MN, USA), the Amulet/Cardiac Plug (St Jude, Golden Valley, MN, USA), the LARIAT ${ }^{\circledR}$ device (SentreHEART, Palo Alto, CA, USA), and the LAmbre device (Lifetech Scientific Corp, People's Republic of China) (Table 1).

Cardiac imaging is of primary importance for LAA anatomical characterization, device size choice, ruling out LAA thrombus before the procedure, and minimizing complications. ${ }^{27,28}$ Currently, the best preprocedural imaging modalities are cardiac computed tomography (CCT), ${ }^{29}$ cardiac magnetic resonance, ${ }^{30}$ and three-dimensional TEE. ${ }^{31}$ Two- and three-dimensional TEE are commonly used during LAA closure procedure. ${ }^{32}$

\section{PLAATO}

The PLAATO system was the first approved device for LAA closure (Figure 1A). ${ }^{33}$ It was made up of a self-expanding nitinol cage covered with polytetrafluoroethylene (PTFE). The device production was discontinued in 2007 for commercial reasons.

Two prospective multicenter trials evaluated the efficacy of the PLAATO device. In the international multicenter feasibility trial, ${ }^{34}$ the PLAATO system was used in 111 patients

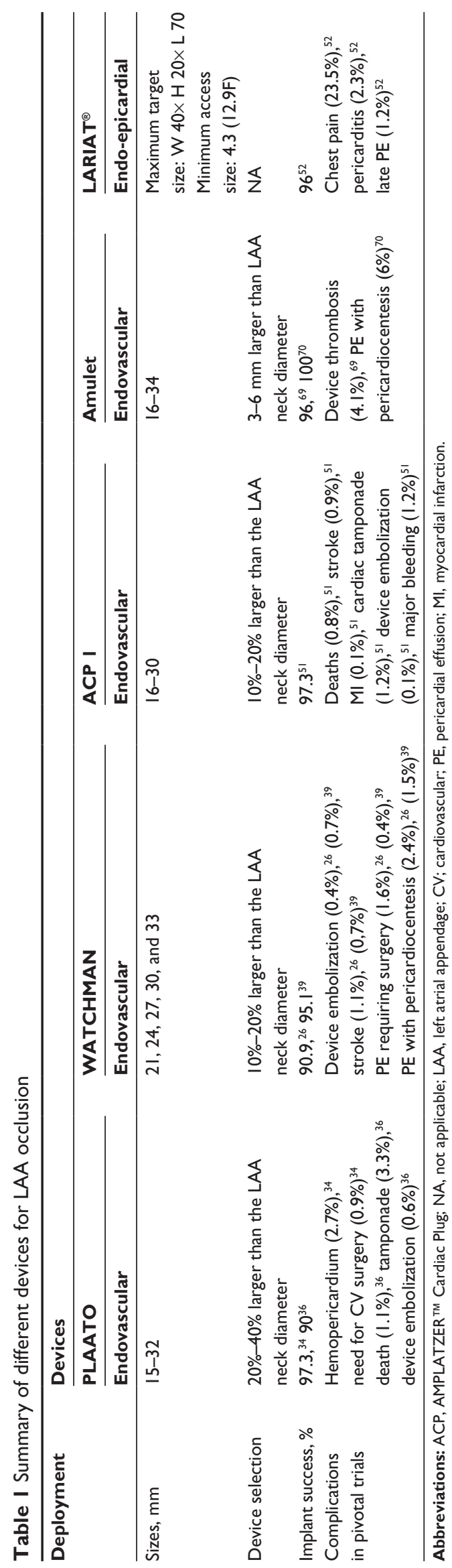




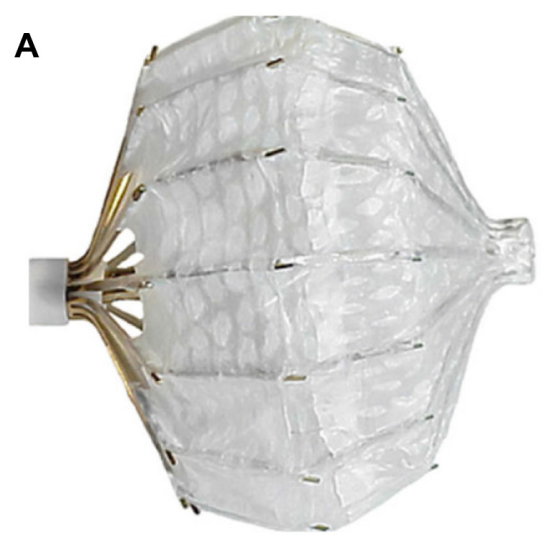

C

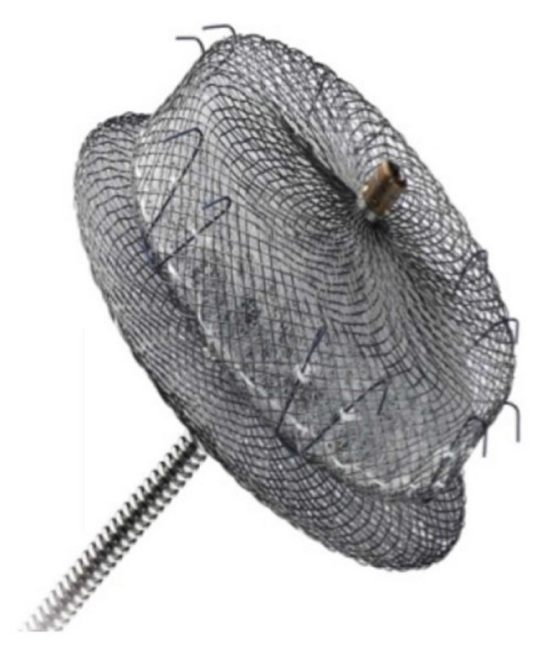

B

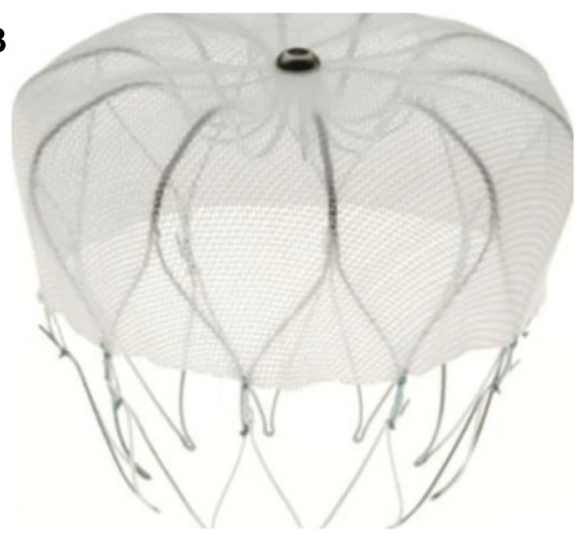

D

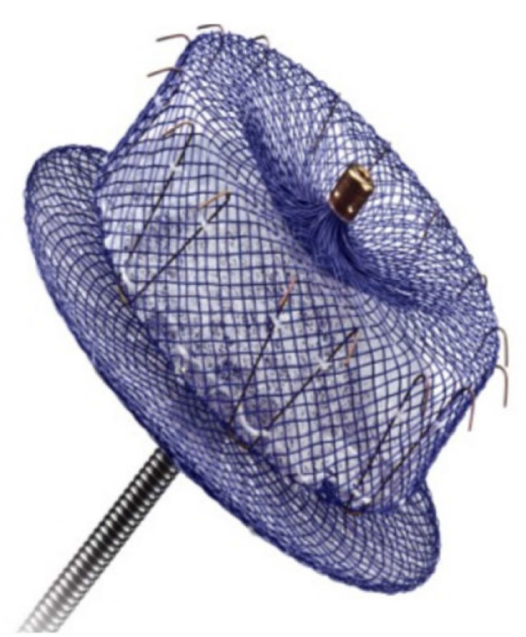

Figure I LAA occlusion devices.

Notes: (A) PLAATO device, (B) WATCHMAN device, (C) AMPLATZER ${ }^{\text {TM }}$ Cardiac Plug I device, (D) Amulet device.

Abbreviation: LAA, left atrial appendage.

with NVAF with contraindications to warfarin therapy. The primary end point was the incidence of major adverse events. Implantation was successful in 108 of 111 patients $(97.3 \%)$. One patient experienced two major adverse events within the first 30 days: need for cardiovascular surgery and inhospital neurological death. Three other patients underwent in-hospital pericardiocentesis due to a hemopericardium, and two patients experienced stroke. After up to 5 years of follow-up, the annualized stroke/transient ischemic attack (TIA) rate was 3.8\%. ${ }^{35}$ The anticipated stroke/TIA rate (with the $\mathrm{CHADS}_{2}$ scoring method) was $6.6 \%$ per year. ${ }^{35}$

The European PLAATO study ${ }^{36}$ enrolled 180 patients with NVAF and contraindications to warfarin. The primary end points were LAA closure (as determined by TEE) at 2 months after the procedure and a stroke rate per 150 patient-years. Complete occlusion was achieved in $90 \%$ of the patients. There were two deaths within 24 hours of the procedure and six cardiac tamponades. Successful occlusion of the LAA was achieved in $90 \%$ of the patients (determined by TEE) at the 2-month follow-up. Over a follow-up period of 129 documented patient-years, three strokes occurred (2.3\% per year). The expected incidence of stroke according to the $\mathrm{CHADS}_{2}$ score was $6.6 \%$ per year.

\section{WATCHMAN}

The WATCHMAN device was specifically designed for percutaneous LAA closure. It consists of a self-expanding nitinol frame and a perforated polyethylene terephthalate (PET) membrane cap that is delivered from the right femoral vein via a transseptal delivery sheath (Figure 1B). The device is fully retrievable prior to the release from the delivery cable. It is available in five sizes, ranging from 21 to $33 \mathrm{~mm}$ in diameter, and is normally selected $10 \%-20 \%$ larger than the LAA neck diameter to ensure stable device positioning. ${ }^{37}$

The feasibility and early experience using the WATCHMAN LAA system were reported in $2007 .{ }^{37}$ In this study, 66 patients underwent device implantation. At 45 days, 93\% (54 of 58) devices showed successful sealing of LAA. 
Two patients experienced device embolization and two patients experienced TIA. There were two cardiac tamponades and two deaths, neither device-related. No strokes were reported during a mean follow-up of $740 \pm 341$ days. Subsequently, two prospective, controlled, randomized trials have evaluated the efficacy of the WATCHMAN device.

The WATCHMAN Left Atrial Appendage System for Embolic Protection in Patients with Atrial Fibrillation (PROTECT-AF) trial ${ }^{26}$ was a prospective multicenter randomized noninferiority trial comparing percutaneous LAA occlusion with the WATCHMAN device vs chronic adjusted-dose warfarin therapy in patients with NVAF. The study population consisted of 707 patients in 59 centers in Europe and the United States, with a $\mathrm{CHADS}_{2}$ score of $\geq 1$ and without contraindication to warfarin. They were randomly assigned in a 2:1 ratio to device implantation or warfarin therapy. Efficacy was assessed by a primary composite end point of stroke, cardiovascular death, and systemic embolism. The primary safety end point consisted of events related to excessive bleeding or procedure-related complications.

Implantation of the device was successful in $88 \%$ (408/463) of patients assigned to this intervention and in $91 \%$ of those in whom it was attempted (408/449). At 1,065 patient-years of follow-up, the primary efficacy event rate was 3.0 per 100 patient-years (95\% credible interval [CrI], 1.9-4.5) in the WATCHMAN group and 4.9 per 100 patient-years in the Warfarin group (rate ratio [RR], 0.62; 95\% CrI, 0.35-1.25), which met the noninferiority end point. In this study, the noninferiority margin for the event RR for the primary effectiveness end point was set at 2.0. This margin is larger than margins typically used in anticoagulation drug trials and meant that the WATCHMAN device could be found noninferior to warfarin, with an event rate up to two times that in the control group. Primary safety events were more frequent in the WATCHMAN group than in the Warfarin group (7.4 per 100 patient-years; 95\% CrI, 5.5-9.7 vs 4.4 per 100 patientyears; 95\% CrI, 2.5-6.7; RR, 1.69, 1.01-3.19). It was mainly a result of periprocedural complications and occurred early in the trial.

In view of these findings, a continued access protocol (CAP) registry ${ }^{38}$ was designed to gain further safety and efficacy data seen in the PROTECT AF trial. This registry included the 542 patients who underwent attempted LAA device closure in the intervention group of the PROTECT AF trial and a further 460 patients from centers that participated in the trial with the same inclusion criteria, follow-up, and medication. The efficacy composite end point was similar to that of PROTECT AF. Results revealed a significant decline in the rate of procedure- or device-related safety events within 7 days of the procedure across the two studies and between the first and second halves of PROTECT AF and CAP.

The PREVAIL study ${ }^{39}$ was designed to further explore the safety and efficacy of the device and confirm an improved procedural safety profile. In this trial, 407 patients with AF who had a $\mathrm{CHADS}_{2}$ score of $\geq 2$ or 1 and another risk factor were randomly assigned to undergo LAA occlusion and subsequent discontinuation of warfarin or receive chronic warfarin therapy.

Implantation of the device was successful in $95 \%$ of the patients in whom it was attempted (252/256). At 18 months, the rate of the first coprimary efficacy end point (composite of stroke, systemic embolism, and cardiovascular/unexplained death) was 0.064 in the WATCHMAN group vs 0.063 in the Warfarin group (RR, 1.07; 95\% CrI, 0.57-1.89) and did not achieve the prespecified criterion noninferiority. The rate of the second coprimary efficacy end point (stroke or systemic embolism $>7$ days postrandomization) was 0.0253 vs 0.0200 (risk difference, 0.0053 ; $95 \% \mathrm{CrI},-0.0190$ to 0.0273 ), achieving noninferiority. Early safety events occurred in $2.2 \%$ of the WATCHMAN arm, significantly lower than in PROTECT AF, satisfying the prespecified safety performance goal.

Long-term results of PROTECT AF trial have been recently published. ${ }^{40}$ After 3.8 years of follow-up, percutaneous LAA closure met criteria for both noninferiority and superiority, compared with warfarin, for preventing the combined outcome of stroke, systemic embolism, and cardiovascular death, as well as superiority for cardiovascular and all-cause mortality. Efficacy outcomes and complications in the randomized, clinical trials of the WATCHMAN compared with warfarin are shown in Table 2.

\section{AMPLATZER ${ }^{\text {TM }}$ Cardiac Plug}

The AMPLATZER ${ }^{\text {TM }}$ Cardiac Plug (ACP) is a self-expanding nitinol device consisting of a distal lobe and a proximal disk, each with a sewn polyester patch connected by a short central waist (Figure 1C and D). ${ }^{41,42}$ The lobe has diameters of 16-30 $\mathrm{mm} .{ }^{43}$ The ACP has a CE mark, but it has not been approved yet for use in the United States.

The device is delivered from the femoral vein through a transseptal sheath using a combination of fluoroscopic and TEE guidance. It is usually selected to be $10 \%-20 \%$ larger than the narrowest diameter of the LAA neck. ${ }^{44}$ The proximal disc covers the ostium of the LAA from within the left atrium; therefore, the mechanism of LAA occlusion differs 
Table 2 Efficacy outcomes and complications in the randomized, clinical trials of the WATCHMAN compared with Warfarin

\begin{tabular}{|c|c|c|}
\hline & $\begin{array}{l}\text { PROTECT-AF } \\
(\mathrm{n}=707)\end{array}$ & $\begin{array}{l}\text { PREVAIL }^{39} \\
(n=407)\end{array}$ \\
\hline \multirow[t]{2}{*}{ Population studied } & Warfarin eligible & Warfarin eligible \\
\hline & CHADS $_{2}$ score $\geq 1$ & $\begin{array}{l}\mathrm{CHADS}_{2} \text { score } \geq 2 \text { or I plus an additional } \\
\text { risk factor }\end{array}$ \\
\hline Control & Warfarin & Warfarin \\
\hline \multirow[t]{2}{*}{ Primary end point } & CVD, any stroke, or SE & CVD, any stroke, or SE \\
\hline & & Any stroke or $\mathrm{SE}>\mathbf{7}$ days after the procedure \\
\hline Duration of follow-up & I,065 patient-years & $11.8 \pm 5.8 \mathrm{~m}$ \\
\hline \multirow[t]{2}{*}{ RR NI criterion (upper bound of $95 \% \mathrm{Crl}$ ) } & $\mathrm{RR}<2.0$ & $\mathrm{RR},<\mathrm{I} .75$ \\
\hline & & Rate difference, $<0.0275$ \\
\hline \multirow[t]{2}{*}{ Treatment effect $(95 \% \mathrm{Crl})$} & RR, $0.62(0.35-1.25)$ & RR, I.07 (0.57-1.89) \\
\hline & & Difference, 0.0053 (-0.0190 to 0.0273$)$ \\
\hline \multirow[t]{2}{*}{$\mathrm{Nl}$ achieved? } & Yes & No \\
\hline & & Yes \\
\hline All 7-day procedural complications (\%) & 8.7 & 4.5 \\
\hline Procedure-related stroke (\%) & 1.1 & 0.7 \\
\hline PE requiring surgery $(\%)$ & 1.6 & 0.4 \\
\hline PE requiring pericardiocentesis (\%) & 2.4 & 1.5 \\
\hline Device embolization (\%) & 0.4 & 0.7 \\
\hline
\end{tabular}

Abbreviations: AF, atrial fibrillation; $\mathrm{Crl}$, credible interval; CVD, cardiovascular death; NI, noninferiority; PE, pericardial effusion; RR, rate ratio; SE, systemic embolism; CHADS, Congestive heart failure, Hypertension, Age, Diabetes, Stroke.

from that of the WATCHMAN, which occludes the LAA from within the appendage itself.

A second-generation of the ACP (ACP2 or Amulet) was designed with strategic modifications to facilitate the implantation process and minimize the occurrence of complications. The Amulet has a lightly longer distal lobe, a longer central waist, and a larger-diameter proximal disk. Also, it has stiffer hooks, and the number of stabilizing wires has been increased from 6 pairs in the ACP1 to up to 10 pairs. ${ }^{41}$ It is fully retrievable and repositionable $\mathrm{e}^{41}$ and is recommended that the device be selected such that it is approximately 3-6 mm larger than the LAA neck. ${ }^{41}$

Data regarding the safety and efficacy of the ACP are limited to observational studies. ${ }^{42-49}$ Park et al ${ }^{42}$ reported that LAA occlusion using the ACP device was successfully performed in 132 of 137 patients (96\%). There were serious complications in $10(7.0 \%)$ patients (three patients had ischemic stroke, two patients experienced device embolization, and five patients had clinically significant pericardial effusions). In a retrospective study, Nietlispach et $\mathrm{al}^{48}$ evaluated 152 patients who received ACP device implantation. The short-term safety end points (procedural complications, bleeds) occurred in 15/152 (9.8\%) and the efficacy end points (death, stroke, systemic embolization) in 0 patients. Device embolization occurred in $4.6 \%$ (7/152) of patients. Mean intermediate-term follow-up of the study population was 32 months (range, 1-120). Late deaths occurred in 15 patients, neurologic events occurred in 2, peripheral embolism in 1, and major bleeding in 4 patients.

In the AMPLATZERTM Cardiac Plug European Multicenter Observational Study, ${ }^{50}$ a total of 197 patients underwent ACP implantation in Europe in 2009-2011. The majority of patients $(57.9 \%)$ had a history of permanent AF, and the mean age was $74.20 \pm 9.0$ and the mean $\mathrm{CHADS}_{2}$ score was 2.6 \pm 1.3 . The ACP device was successfully implanted in $96.6 \%$ of patients, with a closure rate of $99.5 \%$ at implant and $98.9 \%$ at 6 months. Device/procedure-related safety events included $0(0.0 \%)$ periprocedural strokes, $3(1.5 \%)$ serious pericardial effusions, 5 (2.4\%) device-related thrombus, and $3(1.5 \%)$ device embolizations. The stroke rate was $1.98 \%$ at 101 patient-years compared with a $\mathrm{CHADS}_{2}$ prediction of $5.6 \%$.

Recently, Tzikas et $\mathrm{al}^{51}$ presented the data from 1,047 consecutive patients treated in 22 centers. Procedural success was $97.3 \%$, and there were $45(4.3 \%)$ periprocedural major adverse events: 8 deaths $(0.8 \%), 9$ strokes $(0.9 \%), 1$ myocardial infarction $(0.1 \%), 13$ cardiac tamponades $(1.2 \%)$, 13 major bleeding episodes (1.2\%), and 1 device embolization needing surgery $(0.1 \%)$. Follow-up was complete in $98.2 \%$ of successfully implanted patients (average, 13 months - a total of 1,349 patient-years). One-year all-cause mortality was $4.2 \%$, and no death at follow-up was reported as device related. There were 9 strokes $(0.9 \%)$ and 9 TIAs, and the annual rate of systemic thromboembolism (periprocedural and follow-up) was $2.3 \%$, which is a $59 \%$ risk reduction. 


\section{LARIAT $^{\circledR}$}

The LARIAT ${ }^{\circledR}$ system device requires both epicardial and endocardial approaches to occlude the LAA (Figure 2A). The device has three components: 1) a $20 \mathrm{~mm}$ compliant occlusion balloon, 2) 0.025-inch and 0.035-inch magnettipped guidewires, and 3) a $12 \mathrm{~F}$ suture delivery device. Four steps are required: 1) accessing the pericardial and transseptal spaces, 2) placing the endocardial magnettipped guidewire in the apex of the LAA with balloon identification of the LAA, 3) connection of the epicardial and endocardial magnet-tipped guidewires for stabilization of the LAA, and 4) snare capture of the LAA with closure confirmation and release of the pre-tied suture for LAA ligation. ${ }^{52}$ Preprocedural CCT imaging is mandatory to assess anatomic eligibility. Contraindications to this approach include an LAA width greater than $40 \mathrm{~mm}$, a superiorly oriented LAA, and historical conditions that would result in pericardial adhesions.
The initial LARIAT $^{\circledR}$ study was performed from February 2010 to February 2011 in 21 patients with AF. ${ }^{53}$ The LAA was occluded in $100 \%$ of patients. There were no strokes reported during the follow-up period (mean, $352 \pm 143$ days). In another study, ${ }^{54} 27$ patients with AF and OAC therapy contraindications or intolerance were selected. Preserved LAA closure was confirmed with a 45-day follow-up TEE in 22 of 25 patients completing the procedure. In a major study conducted by Bartus et al, ${ }^{52}$ LAA ligation was successful in 85 of 89 patients $(96 \%)$. Eighty-one of 85 patients had complete closure (determined by TEE imaging) immediately after the procedure. Of the patients undergoing 1-year TEE (65), there was $98 \%$ complete LAA closure.

Complications of using LARIAT $^{\circledR}$ include pericarditis, ${ }^{53}$ thrombogenicity at the endocardial site in the left atrium, ${ }^{55,56}$ partial reopening of the LAA, ${ }^{57}$ and laceration and cardiac tamponade. ${ }^{58}$
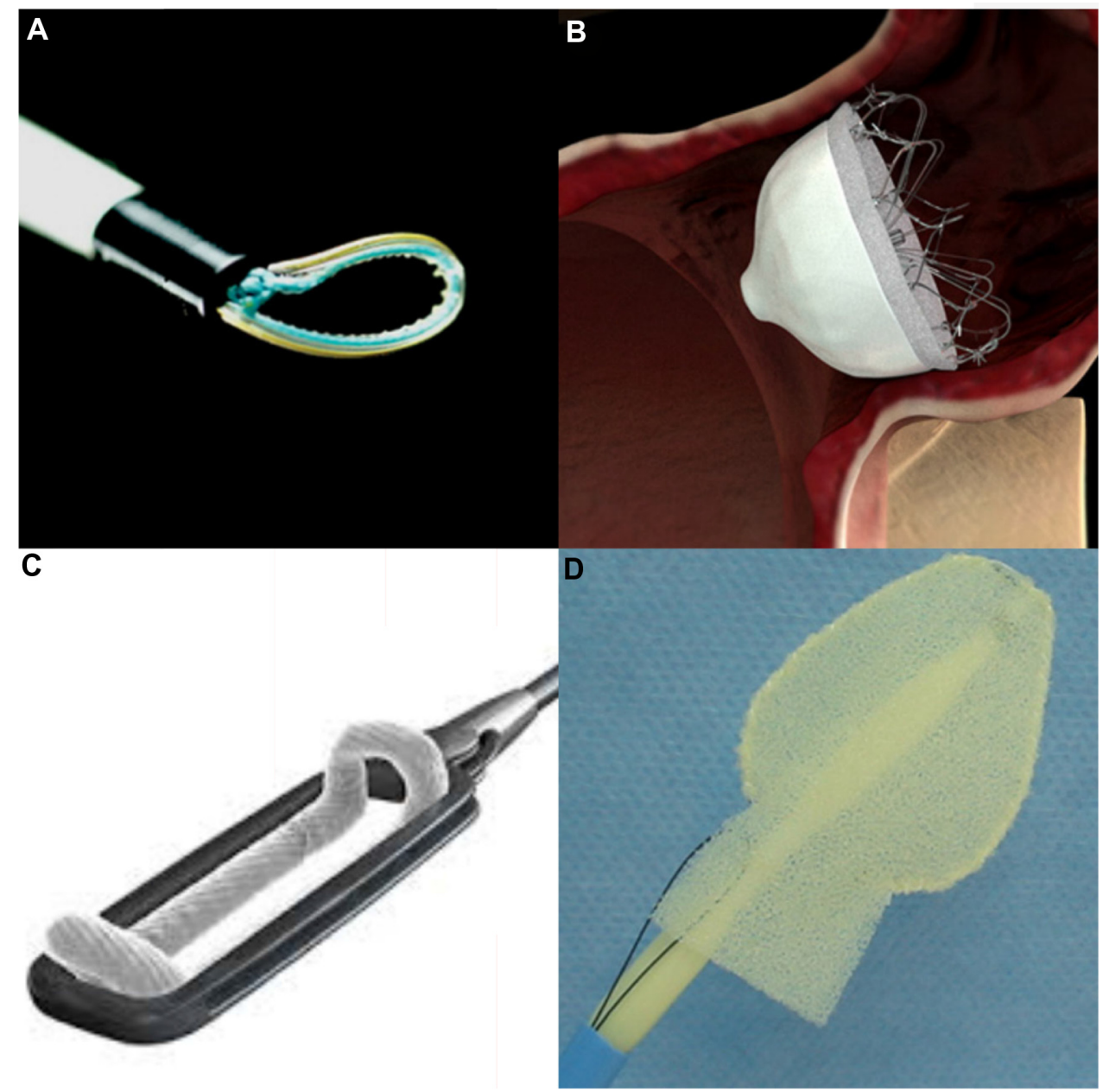

Figure 2 LAA occlusion devices.

Notes: (A) LARIAT ${ }^{\circledR}$ device, (B) WaveCrest ${ }^{\circledR}$ device, (C) AtriClip device, (D) Transcatheter Patch device.

Abbreviation: LAA, left atrial appendage. 


\section{LAmbre}

LAmbre is a self-expanding LAA occluder constructed from a nitinol mesh and polyester membranes and consists of an umbrella and a cover connected by a short central waist. The device comes in various sizes, ranging from 16 to $36 \mathrm{~mm}$. It is delivered by an $8 \mathrm{~F}-10 \mathrm{~F}$ sheath and has fully recapturable and repositioning capabilities. ${ }^{59}$ The Feasibility and Safety Study of LAmbre Left Atrial Appendage Occluder trial is currently recruiting participants (ClinicalTrials.gov; identifier: NCT01920412).

\section{Other devices}

The WaveCrest ${ }^{\circledR}$ device (Coherex Medical, Salt Lake City, UT, USA) consists of a nitinol structure without exposed metal hub and with a foam layer facing the LAA and a PTFE layer facing the left atrium (Figure 2B). ${ }^{60}$ The WaveCrest ${ }^{\circledR} \mathrm{I}$ trial ${ }^{61}$ recruited 73 patients from Europe, Australia, and New Zealand, with a mean CHADS, score of 2.5 , previous cerebral embolism in $34 \%$, and a warfarin contraindication in $49 \%$. Successful deployment with acute closure was seen in 68 of 73 (93\%). Acute tamponade occurred in 2 of $73(3 \%)$, and there was no procedural stroke, device embolization, or device-related thrombosis. The WaveCrest ${ }^{\circledR}$ device received a CE mark in 2013.

The AtriClip (Atricure Inc, West Chester, OH, USA) device is a clip made of two parallel rigid titanium tubes with elastic nitinol springs covered with a knit-braided polyester sheath (Figure 2C). It is placed epicardially around the LAA and compresses the appendage at its base. The EXCLUDE clinical trial (Exclusion of Left Atrial Appendage with AtriClip Exclusion Device in Patients Undergoing Concomitant Cardiac Surgery) was a nonrandomized, multicenter trial designed to assess the safety and efficacy of this device. ${ }^{62}$ A total of 71 patients undergoing open cardiac surgery were enrolled in the study. Intraprocedural success occurred in 67 of 70 patients $(95.7 \%)$, with significant adverse events occurring in $48.6 \%$, which were not device related. At 3-month follow-up of 65 of 70 patients, 1 case of mortality was reported. Sixty-one patients underwent computed tomographic angiography or TEE, and $60(98.4 \%)$ had successful LAA occlusion. The AtriClip device was approved by the US Food and Drug Administration for LAA occlusion under direct visualization, in conjunction with other open-heart cardiac procedures. The Transcatheter Patch (Custom Medical Devices, Athens, Greece) is a frameless, bioabsorbable, balloon-deliverable device that can be adjusted for the shape and size of the appendage without the risk of perforation (Figure 2D). It was studied in 20 patients, showing successful placement in 17 cases. $^{63}$

The Aegis system is an epicardial electrocardiographyguided LAA capture and ligation system. It permits LAA closure in the closed pericardial space with a single sheath puncture. ${ }^{64,65}$

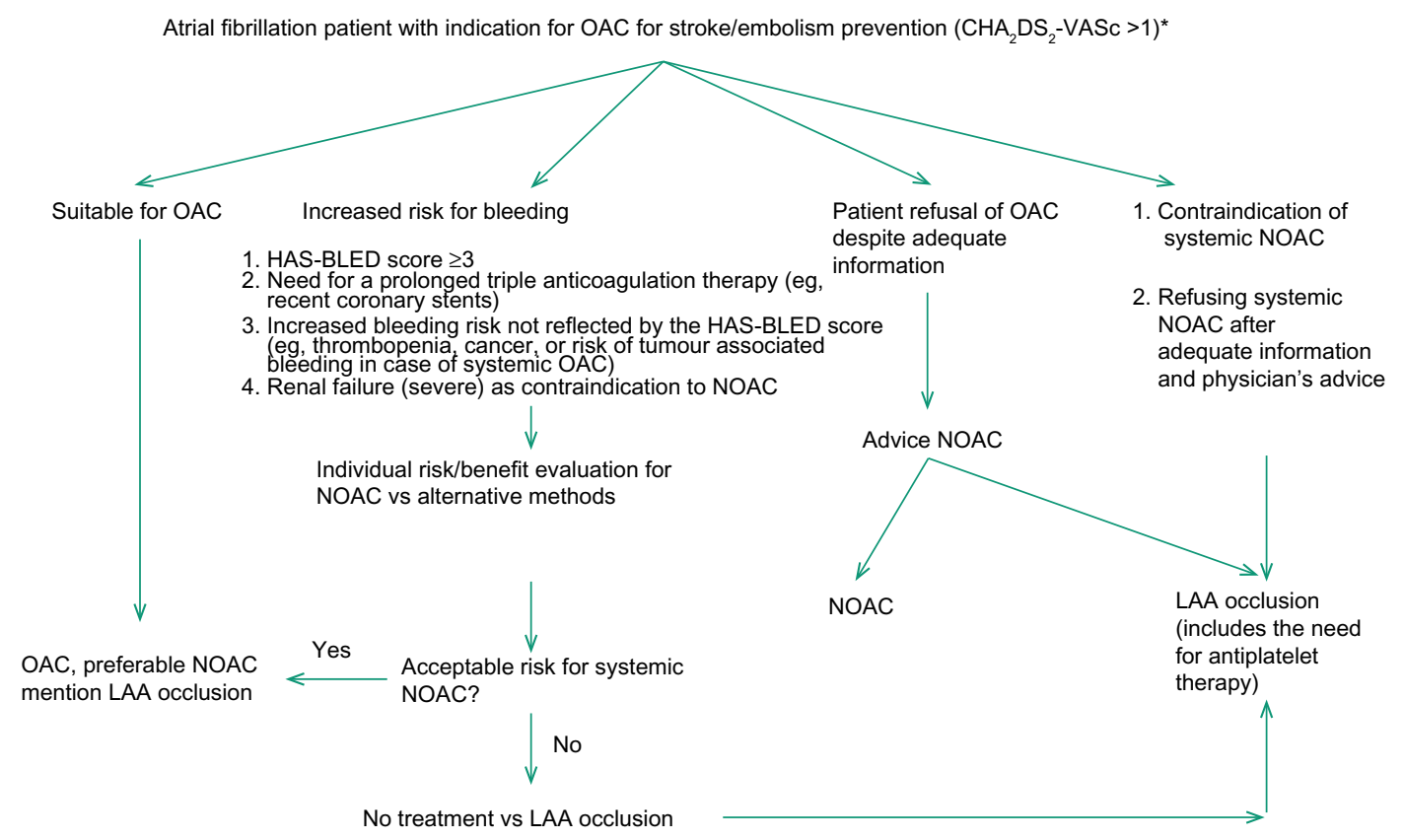

Figure 3 Algorithm for stroke prevention in patients with atrial fibrillation.

Note: In all: adequate and intensified rhythm control (ablation or amiodarone) in combination with continuous rhythm control by implanted devices with remote monitoring. Reprinted from Eurolntervention 16(10), Meier B, Blaauw Y, Khattab AA, et al, EHRA/EAPCl expert consensus statement on catheter-based left atrial appendage occlusion, 1397-1416. Copyright (C) 2014, with permission from Europa Digital \& Publishing. ${ }^{68}$

Abbreviations: LAA, left atrial appendage; NOAC, novel (nonvitamin K antagonist) oral anticoagulant; OAC, oral anticoagulant. 


\section{Indications for left atrial appendage occlusion}

A recent systematic review suggested comparable efficacy of LAA occlusion devices compared with anticoagulation strategies for prevention of stroke in patients with NVAF. ${ }^{66}$ Also, percutaneous LAA occlusion is cost-effective compared with warfarin. ${ }^{67}$

The percutaneous LAA closure as an alternative to OAC when OACs are not contraindicated is the only potential indication that is currently based on randomized controlled data. ${ }^{26,39}$ However, the main indication for LAA occlusion is a relative or absolute contraindication to OACs (eg, a history of a significant bleeding or life-threatening bleeding) in patients with $\mathrm{AF}$ and a $\mathrm{CHADS}_{2}$ score of $\geq 1$ or a $\mathrm{CHA}_{2}-\mathrm{DS}_{2}$-VASc score of $\geq 2$. This recommendation is based on observational studies and registries only.

An EHRA/EAPCI expert consensus statement on catheter-based LAA occlusion has been recently published, and it summarizes the recommended current indications (Figure 3). ${ }^{68}$

\section{Conclusion and future directions}

Stroke is the most serious complication of AF. The main treatment for stroke prevention in AF patients is OAC, which has proven efficacy. However, multiple adverse effects limit its use. Percutaneous LAA closure devices have been developed as a nonpharmacologic alternative to warfarin for stroke prevention in patients with $\mathrm{AF}$. Reported results confirm the technical feasibility of percutaneous LAA closure and its effectiveness in preventing ischemic stroke. To get good results, a team with experience and a substantial learning curve for the operator are critical.

In future studies, it will be important to identify patients who may benefit most from percutaneous LAA closure as a valid strategy for the prevention of stroke, try to minimize periprocedural complications, and contribute to improving the design of the LAA closure devices. Also, prospective head-to-head comparisons among devices and using the novel OACs are needed.

\section{Disclosure}

Dr Cruz-Gonzalez is proctor and consultant for St Jude Medical and Boston Scientific. The authors report no other conflicts of interest in this work.

\section{References}

1. Stewart S, Hart CL, Hole DJ, McMurray JJ. A population-based study of the long-term risks associated with atrial fibrillation: 20-year follow-up of the Renfrew/Paisley study. Am J Med. 2002;113(5):359-364.
2. Benjamin EJ, Wolf PA, D’Agostino RB, Silbershatz H, Kannel WB, Levy D. Impact of atrial fibrillation on the risk of death: the Framingham Heart Study. Circulation. 1998;98(10):946-952.

3. Go AS, Mozaffarian D, Roger VL, et al. Heart disease and stroke statistics - 2013 update: a report from the American Heart Association. Circulation. 2013;127(1):6-245.

4. Wolf PA, Abbott RD, Kannel WB. Atrial fibrillation as an independent risk factor for stroke: the Framingham Study. Stroke. 1991;22(8): 983-988.

5. Lin HJ, Wolf PA, Kelly-Hayes M, et al. Stroke severity in atrial fibrillation. The Framingham Study. Stroke. 1996;27(10):1760-1764.

6. Hart RG, Pearce LA, Rothbart RM, McAnulty JH, Asinger RW, Halperin JL. Stroke with intermittent atrial fibrillation: incidence and predictors during aspirin therapy. Stroke Prevention in Atrial Fibrillation Investigators. $J$ Am Coll of Cardiol. 2000;35(1): 183-187.

7. Hohnloser SH, Pajitnev D, Pogue J, et al. Incidence of stroke in paroxysmal versus sustained atrial fibrillation in patients taking oral anticoagulation or combined antiplatelet therapy: an ACTIVE W Substudy. J Am Coll Cardiol. 2007;50(22):2156-2161.

8. Friberg L, Hammar N, Rosenqvist M. Stroke in paroxysmal atrial fibrillation: report from the Stockholm Cohort of Atrial Fibrillation. Eur Heart J. 2010;31(8):967-975.

9. Lip GY, Nieuwlaat R, Pisters R, Lane DA, Crijns HJ. Refining clinical risk stratification for predicting stroke and thromboembolism in atrial fibrillation using a novel risk factor-based approach: the Euro heart survey on atrial fibrillation. Chest. 2010;137(2):263-272.

10. Samsa GP, Matchar DB, Goldstein LB, et al. Quality of anticoagulation management among patients with atrial fibrillation: results of a review of medical records from 2 communities. Arch Inter Med. 2000;160(7): 967-973.

11. Casciano JP, Dotiwala ZJ, Martin BC, Kwong WJ. The costs of warfarin underuse and nonadherence in patients with atrial fibrillation: a commercial insurer perspective. J Manag Care Pharm. 2013;19(4): 302-316.

12. Gladstone DJ, Bui E, Fang J, et al. Potentially preventable strokes in high-risk patients with atrial fibrillation who are not adequately anticoagulated. Stroke. 2009;40(1):235-240.

13. Connolly S, Pogue J, Hart R, et al. Clopidogrel plus aspirin versus oral anticoagulation for atrial fibrillation in the Atrial fibrillation Clopidogrel Trial with Irbesartan for prevention of Vascular Events (ACTIVE W): a randomised controlled trial. Lancet. 2006;367(9526): 1903-1912.

14. The SPAF III Writing Committee for the Stroke Prevention in Atrial Fibrillation Investigators. Patients with nonvalvular atrial fibrillation at low risk of stroke during treatment with aspirin: Stroke Prevention in Atrial Fibrillation III Study. JAMA. 1998;279(16): 1273-1277.

15. Connolly SJ, Ezekowitz MD, Yusuf S, et al. Dabigatran versus warfarin in patients with atrial fibrillation. $N$ Engl J Med. 2009;361(12): $1139-1151$.

16. Granger $\mathrm{CB}$, Alexander JH, McMurray JJ, et al. Apixaban versus warfarin in patients with atrial fibrillation. $N$ Engl J Med. 2011;365(11): 981-992.

17. Patel MR, Mahaffey KW, Garg J, et al. Rivaroxaban versus warfarin in nonvalvular atrial fibrillation. $N$ Engl $J$ Med. 2011;365(10): 883-891.

18. Bungard TJ, Ghali WA, Teo KK, McAlister FA, Tsuyuki RT. Why do patients with atrial fibrillation not receive warfarin? Arch Intern Med. 2000;160(1):z41-z46.

19. Giugliano RP, Ruff CT, Braunwald E, et al. Edoxaban versus warfarin in patients with atrial fibrillation. N Engl J Med. 2013;369(22): 2093-2104.

20. Granger CB, Armaganijan LV. Newer oral anticoagulants should be used as first-line agents to prevent thromboembolism in patients with atrial fibrillation and risk factors for stroke or thromboembolism. Circulation. 2012;125(1):159-164. 
21. Mugge A, Kuhn H, Nikutta P, Grote J, Lopez JA, Daniel WG. Assessment of left atrial appendage function by biplane transesophageal echocardiography in patients with nonrheumatic atrial fibrillation: identification of a subgroup of patients at increased embolic risk. J Am Coll Cardiol. 1994;23(3):599-607.

22. Pollick C, Taylor D. Assessment of left atrial appendage function by transesophageal echocardiography. Implications for the development of thrombus. Circulation. 1991;84(1):223-231.

23. Stoddard MF, Dawkins PR, Prince CR, Ammash NM. Left atrial appendage thrombus is not uncommon in patients with acute atrial fibrillation and a recent embolic event: a transesophageal echocardiographic study. J Am Coll Cardiol. 1995;25(2):452-459.

24. Manning WJ, Silverman DI, Gordon SP, Krumholz HM, Douglas PS. Cardioversion from atrial fibrillation without prolonged anticoagulation with use of transesophageal echocardiography to exclude the presence of atrial thrombi. $N$ Engl J Med. 1993;328(11): 750-755.

25. Blackshear JL, Odell JA. Appendage obliteration to reduce stroke in cardiac surgical patients with atrial fibrillation. Ann Thorac Surg. 1996;61(2):755-759.

26. Holmes DR, Reddy VY, Turi ZG, et al. Percutaneous closure of the left atrial appendage versus warfarin therapy for prevention of stroke in patients with atrial fibrillation: a randomised non-inferiority trial. Lancet. 2009;374(9689):534-542.

27. Agner BF, Kuhl JT, Linde JJ, et al. Assessment of left atrial volume and function in patients with permanent atrial fibrillation: comparison of cardiac magnetic resonance imaging, 320-slice multi-detector computed tomography, and transthoracic echocardiography. Eur Heart $J$ Cardiovasc Imaging. 2014;15(5):532-540.

28. Park YM, Kim MN, Choi JI, et al. Intra-procedural imaging of the left atrium and pulmonary veins with rotational angiography: a comparison of anatomy obtained by pre-procedural cardiac computed tomography and trans-thoracic echocardiography. Int J Cardiovasc Imaging. 2013 29(7):1423-1432.

29. Wang Y, Di Biase L, Horton RP, Nguyen T, Morhanty P, Natale A. Left atrial appendage studied by computed tomography to help planning for appendage closure device placement. J Cardiovasc Electrophysiol. 2010;21(9):973-982.

30. Heist EK, Refaat M, Danik SB, Holmvang G, Ruskin JN, Mansour M. Analysis of the left atrial appendage by magnetic resonance angiography in patients with atrial fibrillation. Heart Rhythm. 2006;3(11): 1313-1318.

31. Nakajima H, Seo Y, Ishizu T, et al. Analysis of the left atrial appendage by three-dimensional transesophageal echocardiography. Am J Cardiol. 2010;106(6):885-892.

32. Chue CD, de Giovanni J, Steeds RP. The role of echocardiography in percutaneous left atrial appendage occlusion. Eur J Echocardiogr. 2011;12(10):i3-i10.

33. Sievert H, Lesh MD, Trepels T, et al. Percutaneous left atrial appendage transcatheter occlusion to prevent stroke in high-risk patients with atrial fibrillation: early clinical experience. Circulation. 2002;105(16): 1887-1889.

34. Ostermayer SH, Reisman M, Kramer PH, et al. Percutaneous left atrial appendage transcatheter occlusion (PLAATO system) to prevent stroke in high-risk patients with non-rheumatic atrial fibrillation: results from the international multi-center feasibility trials. J Am Coll Cardiol. 2005;46(1):9-14.

35. Block PC, Burstein S, Casale PN, et al. Percutaneous left atrial appendage occlusion for patients in atrial fibrillation suboptimal for warfarin therapy: 5-year results of the PLAATO (Percutaneous Left Atrial Appendage Transcatheter Occlusion) Study. JACC Cardiovasc Interv. 2009;2(7):594-600.

36. Bayard YL, Omran H, Neuzil P, et al. PLAATO (Percutaneous Left Atrial Appendage Transcatheter Occlusion) for prevention of cardioembolic stroke in non-anticoagulation eligible atrial fibrillation patients: results from the European PLAATO study. EuroIntervention. 2010; 6(2):220-226.
37. Sick PB, Schuler G, Hauptmann KE, et al. Initial worldwide experience with the WATCHMAN left atrial appendage system for stroke prevention in atrial fibrillation. $J$ Am Coll Cardiol. 2007;49(13):1490-1495.

38. Reddy VY, Holmes D, Doshi SK, Neuzil P, Kar S. Safety of percutaneous left atrial appendage closure: results from the Watchman Left Atrial Appendage System for Embolic Protection in Patients with AF (PROTECT AF) clinical trial and the Continued Access Registry. Circulation. 2011;123(4):417-424.

39. Holmes DR Jr, Kar S, Price MJ, et al. Prospective randomized evaluation of the Watchman Left Atrial Appendage Closure device in patients with atrial fibrillation versus long-term warfarin therapy: the PREVAIL trial. J Am Coll Cardiol. 2014;64(1):1-12.

40. Reddy VY, Sievert H, Halperin J, et al. Percutaneous left atrial appendage closure vs warfarin for atrial fibrillation: a randomized clinical trial. JAMA. 2014;312(19):1988-1998.

41. Freixa X, Chan JL, Tzikas A, Garceau P, Basmadjian A, Ibrahim R. The Amplatzer Cardiac Plug 2 for left atrial appendage occlusion: novel features and first-in-man experience. EuroIntervention. 2013;8(9): 1094-1098.

42. Park JW, Bethencourt A, Sievert H, et al. Left atrial appendage closure with Amplatzer cardiac plug in atrial fibrillation: initial European experience. Catheter Cardiovasc Interv. 2011;77(5):700-706.

43. Lam YY, Yip GW, Yu CM, et al. Left atrial appendage closure with AMPLATZER cardiac plug for stroke prevention in atrial fibrillation: initial Asia-Pacific experience. Catheter Cardiovasc Interv. 2012;79(5): 794-800.

44. Meerkin D, Butnaru A, Dratva D, Bertrand OF, Tzivoni D. Early safety of the Amplatzer Cardiac Plug for left atrial appendage occlusion. Int J Cardiol. 2013;168(4):3920-3925.

45. Guerios EE, Schmid M, Gloekler S, et al. Left atrial appendage closure with the Amplatzer cardiac plug in patients with atrial fibrillation. Arq Bras Cardiol. 2012;98(6):528-536.

46. Lopez-Minguez JR, Eldoayen-Gragera J, Gonzalez-Fernandez R, et al. Immediate and one-year results in 35 consecutive patients after closure of left atrial appendage with the Amplatzer cardiac plug. Rev Esp Cardiol. 2013;66(2):90-97.

47. Urena M, Rodes-Cabau J, Freixa X, et al. Percutaneous left atrial appendage closure with the AMPLATZER cardiac plug device in patients with nonvalvular atrial fibrillation and contraindications to anticoagulation therapy. J Am Coll Cardiol. 2013;62(2):96-102.

48. Nietlispach F, Gloekler S, Krause R, et al. Amplatzer left atrial appendage occlusion: single center 10-year experience. Catheter Cardiovasc Interv. 2013;82(2):283-289.

49. Danna P, Proietti R, Sagone A, et al. Does left atrial appendage closure with a cardiac plug system reduce the stroke risk in nonvalvular atrial fibrillation patients? A single-center case series. Pacing Clin Electrophysiol. 2013;36(3):347-353.

50. Park JW. Results of the AMPLATZER cardiac plug european multicenter observational study. Presented at: The Transcatheter Cardiovascular Therapeutics Conference; October 7, 2012; Miami, FL.

51. Tzikas A, Sievert H, Omran H, et al. Left atrial appendage occlusion for stroke prevention in atrial fibrillation: multicenter experience with the Amplatzer Cardiac Plug [oral presentation-interventions for structural heart disease]. EuroIntervention. EuroPCR Abstracts and Posters 2014 May 2014

52. Bartus K, Han FT, Bednarek J, et al. Percutaneous left atrial appendage suture ligation using the LARIAT device in patients with atrial fibrillation: initial clinical experience. J Am Coll Cardiol. 2013;62(2): 108-118.

53. Massumi A, Chelu MG, Nazeri A, et al. Initial experience with a novel percutaneous left atrial appendage exclusion device in patients with atrial fibrillation, increased stroke risk, and contraindications to anticoagulation. Am J Cardiol. 2013;111(6):869-873.

54. Stone D, Byrne T, Pershad A. Early results with the LARIAT device for left atrial appendage exclusion in patients with atrial fibrillation at high risk for stroke and anticoagulation. Catheter Cardiovasc Interv. Epub June 13, 2013. 
55. Giedrimas E, Lin AC, Knight BP. Left atrial thrombus after appendage closure using LARIAT. Circ Arrhythm Electrophysiol. 2013;6(4): 52-53.

56. Briceno DF, Fernando RR, Laing ST. Left atrial appendage thrombus post LARIAT closure device. Heart Rhythm. 2014;11(9):1600-1601.

57. Di Biase L, Burkhardt JD, Gibson DN, Natale A. 2D and 3D TEE evaluation of an early reopening of the LARIAT epicardial left atrial appendage closure device. Heart Rhythm. 2014;11(6): 1087-1088.

58. Keating VP, Kolibash CP, Khandheria BK, Bajwa T, Sra J, Kress DC. Left atrial laceration with epicardial ligation device. Ann Thorac Cardiovasc Surg. Epub November 8, 2013.

59. Lam YY. A new left atrial appendage occluder (Lifetech LAmbre Device) for stroke prevention in atrial fibrillation. Cardiovasc Revasc Med. 2013;14(3):134-136.

60. Franzen O, Reddy V, Worthley S, et al. Clinical experience with the Coherex WaveCrest ${ }^{\mathrm{TM}}$ LAA occlusion system. Acute results from the WaveCrest I trial. Presented at: Scientific Session at EuroPCR; May 20, 2013; Paris, France.

61. Reddy VY, Franzen O, Worthley S, et al. Clinical experience with the Wavecrest LA appendage occlusion device for stroke prevention in AF: acute results of the WAVECREST I trial. Presented at: The Heart Rhythm Society's 35th Annual Scientific Sessions; May 7, 2014; San Francisco, CA.

62. Ailawadi G, Gerdisch MW, Harvey RL, et al. Exclusion of the left atrial appendage with a novel device: early results of a multicenter trial. J Thorac Cardiovasc Surg. 2011;142(5):1002-1009.
63. Toumanides S, Sideris EB, Agricola T, Moulopoulos S. Transcatheter patch occlusion of the left atrial appendage using surgical adhesives in high-risk patients with atrial fibrillation. J Am Coll Cardiol. 2011; 58(21):2236-2240.

64. Bruce CJ, Stanton CM, Asirvatham SJ, et al. Percutaneous epicardial left atrial appendage closure: intermediate-term results. J Cardiovasc Electrophysiol. 2011;22(1):64-70.

65. Friedman PA, Asirvatham SJ, Dalegrave C, et al. Percutaneous epicardial left atrial appendage closure: preliminary results of an electrogram guided approach. J Cardiovasc Electrophysiol. 2009;20(8):908-915.

66. Bajaj NS, Parashar A, Agarwal S, et al. Percutaneous left atrial appendage occlusion for stroke prophylaxis in nonvalvular atrial fibrillation: a systematic review and analysis of observational studies. JACC Cardiovasc Interv. 2014;7(3):296-304.

67. Singh SM, Micieli A, Wijeysundera HC. Economic evaluation of percutaneous left atrial appendage occlusion, dabigatran, and warfarin for stroke prevention in patients with nonvalvular atrial fibrillation. Circulation. 2013;127(24):2414-2423.

68. Meier B, Blaauw Y, Khattab AA, et al. EHRA/EAPCI expert consensus statement on catheter-based left atrial appendage occlusion. Europace. 2014;16(10):1397-1416.

69. Freixa X, Abualsaud A, Chan J, et al. Left atrial appendage occlusion: initial experience with the Amplatzer ${ }^{\mathrm{TM}}$ Amulet ${ }^{\mathrm{TM}}$. Int $J$ Cardiol. 2014;174(3):492-496.

70. Lam SC, Bertog S, Gafoor S, et al. Left atrial appendage closure using the amulet device: an initial experience with the second generation amplatzer cardiac plug. Catheter Cardiovasc Interv. Epub August 27, 2014.
Research Reports in Clinical Cardiology

\section{Publish your work in this journal}

Research Reports in Clinical Cardiology is an international, peerreviewed, open access journal publishing original research, reports, editorials, reviews and commentaries on all areas of cardiology in the clinic and laboratory. The manuscript management system is completely online and includes a very quick and fair peer-review system.

\section{Dovepress}

Visit http://www.dovepress.com/testimonials.php to read real quotes from published authors. 